\title{
PHOTOSYNTHETIC AND CARBOHYDRATE STATUS OF EASY- AND DIFFICULT-TO-ACCLIMATIZE SEA OATS (UNIOLA PANICULATA L.) GENOTYPES DURING IN VITRO CULTURE AND EX VITRO ACCLIMATIZATION
}

\author{
CARMEN VALERO-ARACAMA ${ }^{1}$, MICHAEL E. KANE ${ }^{1 *}$, SANDRA B. WILSON ${ }^{2}$, JOSEPH C. VU ${ }^{3}$, \\ JOAN ANDERSON ${ }^{3}$, AND NANCY L. PHILMAN ${ }^{1}$ \\ ${ }^{1}$ Department of Environmental Horticulture, Institute of Food and Agricultural Sciences, \\ University of Florida, Gainesville, FL 32611 \\ ${ }^{2}$ Department of Environmental Horticulture, Institute of Food and Agricultural Sciences, \\ University of Florida, IRREC, Fort Pierce, FL 34945 \\ ${ }^{3}$ Department of Agronomy, Institute of Food and Agricultural Sciences, University of Florida, Gainesville, FL 32611
}

(Received 17 January 2006; accepted 21 August 2006; editor B. M. Reed)

\begin{abstract}
Summary
The photosynthetic and carbohydrate status of an easy-to-acclimatize (EK 16-3) and a difficult-to-acclimatize (EK 11-1) genotype of Uniola paniculata L. (sea oats), a native dune species of the southeastern US, were evaluated during in vitro culture and ex vitro acclimatization. Net photosynthetic rate was eight times greater for EK 16-3 than EK 11-1 plantlets after ex vitro transfer. In vitro-produced leaves were morphologically similar to ex vitro-produced leaves and exhibited similar photosynthetic competence. EK 11-1 plantlets exhibited greater transpiration rates at the time of ex vitro transfer than EK 16-3 plantlets. However, the small magnitude of this difference, although significant, indicated that control of water loss was probably not the main cause for poor acclimatization of EK 11-1 plantlets. Carbohydrate analysis in vitro revealed that EK 16-3 plantlets utilized leaf starch reserves more rapidly than EK 11-1 plantlets. Starch utilization correlated with the development of leaves with expanded leaf blades during in vitro rooting in EK 16-3 plantlets. After ex vitro transfer, both genotypes exhibited significant decreases of starch and soluble sugar content in shoots and roots. However, the higher photosynthetic ability of shoots in EK 16-3 resulted in greater accumulation of shoot soluble sugars than EK 11-1 after 2-wk ex vitro culture. After 6-wk in vitro rooting, there were significantly higher chlorophyll and soluble protein contents, ribulose 1,5-bisphosphate carboxylase (rubisco) and phosphoenolpyruvate carboxylase activities in EK 16-3 than EK 11-1 shoots. These differences also correlated with the development of anatomical and morphological leaf features in EK 16-3 similar to those of greenhouse-produced leaves.
\end{abstract}

Key words: micropropagation; phosphoenolpyruvate carboxylase; photosynthesis; rubisco.

\section{INTRODUCTION}

Micropropagation has been used extensively for the rapid production of many plant species and cultivars (Debergh and Zimmerman, 1991; Jeong et al., 1995; Hartmann et al., 2002). However, despite its extraordinary potential, this technology is still problematic. One of the most important problems is the poor survival of plantlets following ex vitro transfer, during acclimatization to greenhouse or field conditions (Pospísilová et al., 1999). This problem originates from the poor development of photosynthetic capacity in vitro, which has been attributed to the presence of sugar in the medium (Kozai, 1991a; Pospíśilová et al., 1992; Arigita et al., 2002), low light and inadequate $\mathrm{CO}_{2}$ supply (Kozai and Iwanami, 1988; De et al., 1993), and poor control of water loss caused by high relative humidity (RH) within the vessel (Desjardins, 1995; Estrada-Luna et al., 2001). These conditions

*Author to whom correspondence should be addressed: Email micropro@ ufl.edu can ultimately influence plant development and photosynthetic performance ex vitro (Kozai, 1991b; Preece and Sutter, 1991).

In vitro culture conditions frequently result in alterations of mesophyll development as well as chloroplast structure, namely grana development (Wetzstein and Sommer, 1982), which may affect the photosynthetic ability of plants. At the biochemical level, low ribulose 1,5-bisphosphate carboxylase/oxygenase (rubisco) activity (Grout, 1988) and high phosphoenolpyruvate carboxylase (PEPC) activity (Triques et al., 1997) are often encountered in $\mathrm{C}_{3}$ species. These conditions also contribute to low photosynthetic activity (Sinha et al., 2002).

During acclimatization, in vitro-cultured plants must go through a transition from a heterotropic or a photomixotrophic mode to a fully photoautotropic mode in the greenhouse. A common strategy of plants during ex vitro acclimatization is to use the carbohydrate storage of in vitro-produced leaves to cover metabolic demands of growing tissues (Piqueras et al., 1998; Van Huylenbroeck et al., 1998; Fuentes et al., 2005). However, the function of in vitroproduced leaves during acclimatization varies depending upon 
plant species. In some plant species, such as Calathea (Calathea loiusae Gagnep. 'Maui Queen'), in vitro-produced leaves have limited photosynthetic ability and function as storage organs whose energy reserves are consumed during the initial days of acclimatization (Van Huylenbroeck et al., 1998). Furthermore, cauliflower (Brassica oleracea L.) or strawberry (Fragaria $\times$ ananassa Duch. 'Kent') leaves exhibit greater respiration than photosynthetic rates and their in vitro-produced leaves senesce rapidly after transplantation ex vitro (Grout and Aston, 1978; Grout and Millam, 1985). However, in other plant species, such as peace lily (Spathiphyllum floribundum Schott. 'Petite'), in vitro leaves are photosynthetically competent and function similarly to greenhouseproduced leaves (Van Huylenbroeck et al., 1998).

Sea oats (Uniola paniculata $\mathrm{L}$.) is a perennial $\mathrm{C}_{4}$ grass native to the southeastern US and commonly used for beach and dune restoration and stabilization (Wagner, 1964; Brown and Smith, 1974). This species is usually propagated by seed. However, alternative vegetative propagation methods are necessary because of the limitation of the natural sources of plants and seeds (Hester and Mendelssohn, 1987; Bachman and Whitwell, 1995; Burgess et al., 2002, 2005). Furthermore, concerns regarding the use of unadapted ecotypes collected from distant locations have also limited the collection of plant materials. Consequently, a micropropagation protocol was developed to mass-produce sea oats genotypes from localized sites (Philman and Kane, 1994). When this protocol was applied to multiple sea oats genotypes, microcuttings of different genotypes transferred ex vitro displayed differing capacities for acclimatization.

Understanding the reasons for the low acclimatization capacity of some sea oats genotypes is needed to produce a wide range of sea oats genotypes efficiently using micropropagation. In the present study, the photosynthetic ability and carbohydrate status, as well as the activity of some key enzymes in the carbon fixation process of $\mathrm{C}_{4}$ plants, were compared between an easy-to-acclimatize sea oats genotype and a difficult-to-acclimatize sea oats genotype.

\section{Materials and Methods}

Culture conditions. Established and indexed in vitro shoot cultures of two sea oats (U. paniculata L.) genotypes, collected from Egmont Key on the Florida Gulf Coast were used. These plants were genotyped using random amplified polymorphic DNA genetic analyses (Ranamukhaarachchi, 2000), and characterized as easy-to-acclimatize and difficult-to-acclimatize (EK 163 and EK 11-1, respectively). Five sea oats shoot clusters, each consisting of three shoots, $25 \mathrm{~mm}$ long, of EK 16-3 and EK 11-1 genotypes, were subcultured into separate Magenta GA7 vessels (Magenta Corp., Chicago, IL, USA) containing $80 \mathrm{ml}$ sterile Stage II medium. Stage II multiplication medium consisted of Murashige and Skoog (MS) inorganic salts (Murashige and Skoog, 1962), supplemented with $87.6 \mathrm{~m} M$ sucrose, $0.56 \mathrm{~m} M$ myoinositol, $1.2 \mu M$ thiamine-HCl, $2.2 \mu M \mathrm{~N}^{6}$-benzyladenine, and gelled with $8 \mathrm{gl}^{-1} \mathrm{TC}^{\mathrm{TM}}$ agar (PhytoTechnology Laboratories, Shawnee Mission, KS, USA). All media were adjusted to $\mathrm{pH} 5.7$ with $0.1 \mathrm{~N} \mathrm{KOH}$ prior to the addition of agar and autoclaving at $117.7 \mathrm{kPa}$ and $121^{\circ} \mathrm{C}$ for $20 \mathrm{~min}$.

Cultures were maintained for $8 \mathrm{wk}$ in a growth chamber at $24 \pm 1^{\circ} \mathrm{C}$, $58 \pm 5 \% \mathrm{RH}, 16-\mathrm{h}$ photoperiod provided by cool-white fluorescent lamps (General Electric F20WT12.CW), and at $40 \pm 5 \mu \mathrm{mol} \mathrm{m}^{-2} \mathrm{~s}^{-1}$ photosynthetic photon flux (PPF) as measured at culture level. Subsequently, the shoot clusters of each genotype were subdivided into single shoots and transferred to Stage III rooting medium.

Stage III rooting medium consisted of $80 \mathrm{ml}$ sterile half-strength MS medium, supplemented with $0.56 \mathrm{~m} M$ myo-inositol, $1.2 \mu M$ thiamine-HCl, $87.6 \mathrm{~m} M$ sucrose, and $10 \mu M \alpha$-naphthaleneacetic acid, gelled with $8 \mathrm{gl}^{-1}$ $\mathrm{TC}^{\mathrm{TM}}$ agar and contained in GA7 vessels. Culture vessels contained eight single microcuttings each, and were maintained in a culture room at $22 \pm 2^{\circ} \mathrm{C}$, under a 16-h photoperiod provided by cool-white fluorescent lamps (General Electric F96T12.CW.WM), at $100 \pm 5 \mu \mathrm{mol} \mathrm{m}^{-2} \mathrm{~s}^{-1} \mathrm{PPF}$, as measured at culture level.

After $6 \mathrm{wk}$, rooted microcuttings were placed individually in 48-cell plug trays (eight six-celled blocks, each cell $4 \times 6 \times 5.5 \mathrm{~cm}$; T.O. Plastics, Inc., Clearwater, MN, USA) containing coarse vermiculite as supporting material and transferred to Stage IV greenhouse conditions. Plantlets were watered as needed and Peters $20 \mathrm{~N}-20 \mathrm{P}-20 \mathrm{~K}$ liquid fertilizer $\left(150 \mathrm{mg} \mathrm{N}^{-1}\right.$; The Scotts Company, Marysville, OH, USA) was applied weekly. Greenhouse set points for cooling and heating were 24 and $22^{\circ} \mathrm{C}$, respectively, and natural solar PPF ranged $900-1200 \mu \mathrm{mol} \mathrm{m}^{-2} \mathrm{~s}^{-1}$ at noon.

Photosynthesis studies. Shoot clusters of the EK 11-1 and EK 16-3 sea oats genotypes were cultured for 8 wk under Stage II conditions as previously described. Subsequently, single microcuttings were transferred to Stage III conditions for $6 \mathrm{wk}$, with 10 replicate GA7 vessels per genotype. All rooted microcuttings were transferred in 48-cell plug trays (eight six-celled blocks, each cell $4 \times 6 \times 5.5 \mathrm{~cm}$; Summit Plastics Inc., Clearwater, OH, USA) to a greenhouse under natural solar PPF ranging between 900 and $1200 \mu \mathrm{mol} \mathrm{m}^{-2} \mathrm{~s}^{-1}$ during the measurements and day/night temperatures of $25 / 22^{\circ} \mathrm{C}$, respectively.

Net photosynthetic rates per leaf area $\left(P_{\mathrm{n}}\right)$ were determined with a PP System Model Ciras-1 (PP System Co., Ltd, UK) without a supplemental light source and inlet $\mathrm{CO}_{2}$ concentration fixed at $400 \pm 10 \mu \mathrm{mol} \mathrm{mol}^{-1}$. Measurements were taken in full sun near midday (10 a.m. to 12 p.m.) on newly formed and fully expanded leaves every week beginning the day after establishment ex vitro. Percent survival was scored every week during Stage IV. Two plants per plug tray were measured, compiling data from 20 plants per genotype. Data were collected weekly for 7 consecutive weeks.

Photosynthesis enzymatic studies. Shoot clusters from EK 11-1 and EK 16-3 were cultured for $8 \mathrm{wk}$ in GA7 vessels under Stage II conditions as previously described. There were four replicate vessels per genotype, each vessel containing five plants. Concurrently, another set of sea oats shoot clusters were cultured for $8 \mathrm{wk}$ under the same conditions for shoot multiplication prior to transfer to Stage III conditions for 3, 6, or $9 \mathrm{wk}$. Each treatment in Stage III consisted of four replicate vessels per genotype, each vessel containing eight microcuttings.

Shoots of EK 11-1 and EK 16-3 cultures from Stages II and III in vitro and Stage IV ex vitro conditions were harvested $3 \mathrm{~h}$ after the beginning of the photoperiod for rubisco and PEPC analyses. Each replicate collected from in vitro conditions consisted of all five shoot clusters per vessel from Stage II or all eight clusters per vessel from Stage III, which were immediately placed in liquid $\mathrm{N}_{2}$. During ex vitro Stage IV, each replicate contained three plants, which were placed in liquid $\mathrm{N}_{2}$ in the greenhouse. Subsequently, all replicates were ground to a fine powder in a mortar cooled with liquid $\mathrm{N}_{2}$ and placed in plastic vials in a $-80^{\circ} \mathrm{C}$ freezer before analyses.

For enzymatic extraction, powdered shoot tissue (c. $225 \mathrm{mg}$ per sample) was placed in a glass mortar with $1.8 \mathrm{ml}$ extraction buffer containing $100 \mathrm{~m} M$ bicine $\left(\mathrm{pH} 8.0\right.$ at $\left.25^{\circ} \mathrm{C}\right), 10 \mathrm{~m} M \mathrm{MgCl}_{2}, 0.1 \mathrm{~m} M$ EDTA, $5 \mathrm{~m} M$ dithiothreitol (DTT), $10 \mathrm{~m} M$ isoascorbate, $2 \%$ PVP-40 (w/v), and 0.1\% TX-100 (w/v). Leaf tissue was ground with extraction buffer on ice for $2 \mathrm{~min}$, transferred into two microfuge tubes, and centrifuged for $45 \mathrm{~s}$. A $0.2-\mathrm{ml}$ aliquot of the supernatant was incubated (on ice for a minimum of $5 \mathrm{~min}$ ) with $0.01 \mathrm{ml}$ $500 \mathrm{~m} M \mathrm{MgCl}_{2}$ plus $0.011 \mathrm{ml} 200 \mathrm{~m} M \mathrm{NaHCO}_{3}$ to obtain fully carbamylated rubisco ('activated extract') prior to assay of rubisco activity. A separate aliquot of the supernatant was held at room temperature for immediate assay for PEPC. Both enzymes were assayed in total volumes of $0.5 \mathrm{ml}$ at $25^{\circ} \mathrm{C}$, in triplicate, and assays were completed within $30 \mathrm{~min}$ from the start of extractions procedure with a Hitachi Model U-2000 Double-Beam UV/VIS Spectrophotometer (Hitachi Instruments, Inc., Danbury, CT, USA).

PEPC was assayed spectrophotometrically at $340 \mathrm{~nm}$ by following the reduction of oxaloacetic acid (OAA) by $\mathrm{NADH}$ in the presence of excess malate dehydrogenase (MDH) (Ashton et al., 1990). The reaction mixture contained $100 \mathrm{~m} M$ bicine (pH 8.0), $10 \mathrm{~m} M \mathrm{MgCl}_{2}, 0.1 \mathrm{~m} M$ EDTA, $10 \mathrm{~m} M$ $\mathrm{NaHCO}_{3}, 5 \mathrm{~m} M$ DTT, $2.5 \mathrm{U} \mathrm{MDH}$, and $0.2 \mathrm{~m} M \mathrm{NADH}$. After the addition of $0.01 \mathrm{ml}$ extract, a steady baseline was established and the reaction was initiated by the addition of phosphoenolpyruvate to a final concentration of $5 \mathrm{~m} M$. The linear decrease in absorbance was recorded over a period of $150 \mathrm{~s}$.

Total rubisco activity (fully activated rubisco) was assayed spectrophotometrically based on the method of Lilley and Walker (1974). This enzyme-linked assay couples the activity of rubisco with the oxidation of NADH 
using 3-phosphoglyceric phosphokinase and glyceraldehyde-3-phosphate dehydrogenase extracted from rabbit muscle (linking enzymes). The linking enzymes were purchased as ammonium sulfate precipitates. Sulfate was removed prior to use either by desalting solubilized precipitates or by dissolving the precipitates in $20 \%$ glycerol solution in buffer (Sharkey et al., 1991). The reaction mixture for measuring rubisco activity contained $100 \mathrm{~m} M$ bicine (pH 8.0), $20 \mathrm{~m} M \mathrm{MgCl}_{2}, 1 \mathrm{~m} M$ EDTA, $20 \mathrm{~m} M \mathrm{NaCl}, 10 \mathrm{~m} M$ $\mathrm{NaHCO}_{3}, 5 \mathrm{~m} M$ DTT, $2.5 \mathrm{~m} M$ ATP, $5 \mathrm{~m} M$ phosphocreatine, $5 \mathrm{U}$ creatine phosphokinase, $5 \mathrm{U}$ of each of the linking enzymes, $0.2 \mathrm{~m} M \mathrm{NADH}$, and $0.6 \mathrm{~m} M$ ribulose 1,5-bisphosphate. After a steady baseline absorbance at $340 \mathrm{~nm}$ was established, the reaction was initiated with $0.011 \mathrm{ml}$ of activated extract. The linear decrease in absorbance resulting from the oxidation of NADH was recorded over a period of $150 \mathrm{~s}$.

Chlorophyll content was determined using the method described by Arnon (1949). From each tube containing the crude extract after grinding, an aliquot of $0.1 \mathrm{ml}$ was transferred to two microfuge tubes, each containing $0.1 \mathrm{ml}$ of water. Subsequently, $0.8 \mathrm{ml}$ of $100 \%$ acetone was added in each tube and incubated in the dark for at least $30 \mathrm{~min}$ in ice. After $3 \mathrm{~min}$ of centrifugation, the supernatant was collected and absorbance was measured at 645 and $663 \mathrm{~nm}$ for total chlorophyll determination. Total soluble protein (TSP) in the extracts was quantified by the dye-binding assay of Bradford (1976) using bovine serum albumin as standard.

Transmission electron micrograph studies. Leaf histological cross sections from EK 11-1 and EK 16-3 microcuttings cultured in vitro in Stage III were obtained to compare bundle sheath chloroplast ultrastructure. Transmission electron microscopy (TEM) was used, for which leaf sections $c$. $2 \mathrm{~mm}$ from the center of the leaf blade were fixed in Trump's fixative solution (McDowell and Trump, 1976). Fixative infiltration was achieved under vacuum for $2 \mathrm{~d}$. Leaf tissues were then rinsed three times in phosphate buffer $(\mathrm{pH} 7.2)$, post-fixed in a $1 \%$ buffered osmium tetroxide solution and then rinsed in phosphate buffer, rinsed three times in distilled water, and dehydrated in a five-step ascending ethyl alcohol series $(25,50,75,95$, and $100 \%$ ), followed by dehydration in $100 \%$ acetone. An enbloc stain of $2 \%$ uranyl acetate was applied between the 75 and 95\% steps of the ethyl alcohol dehydration series. Leaf sections were then embedded in Spurr resin (Spurr, 1969). Ultrathin leaf sections $(70 \mathrm{~nm})$ were cut from the center part of the leaf blade using a Leica Ultracut ultramicrotome R (Leica Microscopy and Scientific Instruments, Deerfield, IL, USA), collected on $0.35 \%$ form var-coated copper grids, stained with methanolic uranyl acetate and lead citrate (Reynolds, 1963). Sections were viewed on a Hitachi H7000 transmission electron microscope (Hitachi Scientific Instruments) at $75 \mathrm{kV}$. Digital micrographs were taken on a BioScan/Digital Micrograph 2.5 (Gatan Inc., Pleasanton, CA, USA) at an exposure level optimized for viewing the outer layer and processed with MEGA View III/AnalySIS 3.1 (Soft Imaging System Corp., Lakewood, CO, USA).

Carbohydrate studies. Plantlets from EK 11-1 and EK 16-3 sea oats genotypes were cultured for 8 wk under Stage II conditions, with 20 replicate vessels per genotype, each containing five shoot clusters. Subsequently, single shoots from each genotype were cultured under Stage III conditions for 3,6, or 9 wk. Each Stage III duration treatment consisted of five replicate vessels per genotype, each containing eight single-shoot microcuttings.

At week 8 of Stage II conditions, clusters of plantlets obtained from five vessels were taken out of the medium, washed, and packaged in aluminum foil envelopes. Every package contained three plantlets (sub-samples), which were collected from the same vessel. Samples were frozen in liquid $\mathrm{N}_{2}$ and stored at $-80^{\circ} \mathrm{C}$ prior to drying in a 10-MR-TR freeze drier (The Virtis Company, Gardiner, NY, USA) for $7 \mathrm{~d}$. Dry weights of each sub-sample were then recorded. At weeks 3, 6, and 9 of Stage III conditions, all plantlets from five vessels were collected and processed in the same way, this time separating roots from shoots.

A parallel study was completed to analyze the carbohydrate status of both genotypes during Stage IV duration. Plantlets from EK 11-1 and EK 16-3 sea oats genotypes were cultured for $8 \mathrm{wk}$ under Stage II conditions, followed by 6 wk Stage III conditions and then transferred to Stage IV conditions for 4 wk. Five replicate samples consisting of three shoots or roots per genotype were collected at weeks 2 and 4 of Stage IV and processed as previously described.

Procedures for total soluble sugar (TSS) extraction were modified following the description by Boersig and Negm (1985) and Miller and Langhans (1989). Glass Pasteur pipettes with glass wool plugs were loaded with $50 \mathrm{mg}$ of each sample. Soluble sugars were extracted with $1.5 \mathrm{ml}$ of methanol:chloroform:water (MCW) [12:5:3 (v/v/v)] overnight. One hundred microliters of mannitol $\left(10 \mathrm{mg} \mathrm{ml}^{-1}\right)$ were added as an internal standard to each sample. One hour extractions were repeated two times with $1.5 \mathrm{ml}$ $\mathrm{MCW}$, followed by two additional MCW $(1.5 \mathrm{ml})$ rinses. Nanopure water $(3.5 \mathrm{ml})$ was added to extract prior to 20 -min centrifugation at $4000 \mathrm{rpm}$. The aqueous phase was removed and applied to polyethylene columns containing $3 \mathrm{ml}$ of a 1:1 methanol:water (MW) solution ( $\mathrm{v} / \mathrm{v})$ and cation and anion exchange resin $(1 \mathrm{ml}$ Amberlite IRA-67 layered with $1 \mathrm{ml}$ Dowex 50-W, Sigma-Aldrich Co., St Louis, MO, USA). Soluble sugars were eluted and rinsed two times with 1:1 MW prior to complete evaporation using a RapidVap vacuum evaporator system (Labconco Corp., Kansas City, MO, USA). The dry residue was resuspended in $1 \mathrm{ml}$ high-pressure liquid chromatography (HPLC)-grade water and filtered through a $0.45 \mu \mathrm{m}$ membrane prior to HPLC injection. TSSs (sucrose, glucose, and fructose) were analyzed using a Waters 2695 High-Pressure Liquid Chromatograph (Waters Technological Corporation, Milford, MA, USA) equipped with a Waters 2414 refractive index detector (Waters Technological Corporation) and two connected BioRad Aminex HPX-87C columns (BioRad Laboratories, Hercules, CA, USA). Column and detector temperatures were maintained at 80 and $50^{\circ} \mathrm{C}$, respectively. HPLC-grade water was used as the mobile phase, at a flow rate of $0.6 \mathrm{ml} \mathrm{min}^{-1}$.

For starch analysis, procedures were modified as described by Haissig and Dickson (1979) and Miller and Langhans (1989). The tissue residue (remaining in pipettes after soluble sugar extraction) was oven-dried overnight at $50^{\circ} \mathrm{C}$, suspended in $4 \mathrm{ml} \mathrm{Na-acetate} \mathrm{buffer}(100 \mathrm{mM}, \mathrm{pH} 4.5)$, and kept in a boiling water bath $\left(90^{\circ} \mathrm{C}\right)$ for $30 \mathrm{~min}$. After cooling to room temperature, $1.0 \mathrm{ml}$ amyloglucosidase solution (from Rhizopus mold, SigmaAldrich Co.) [50 U per assay in $0.1 \mathrm{M}(\mathrm{pH} 4.5)$ Na-acetate buffer] was added to each test tube to hydrolyze starch to glucose. Samples were incubated for $48 \mathrm{~h}$ at $55^{\circ} \mathrm{C}$ with occasional agitation. An aliquot $(100 \mu \mathrm{l})$ of each sample (glucose hydrolyzate) was transferred to a clean test tube and subjected to an enzyme assay containing glucose oxidase $\left(5 \mathrm{U} \mathrm{ml}^{-1}\right)$ and peroxidase $\left(200 \mathrm{U} \mathrm{ml}^{-1}\right)$. After the addition of $2.2 \mathrm{~N} \mathrm{HCl}(1.0 \mathrm{ml})$, absorbance at $450 \mathrm{~nm}$ was determined using a Beckman DU-64 spectrophotometer (Beckman Coulter Inc., Fullerton, CA, USA) and starch content was calculated based on the regression equation of the glucose calibration line $(0.0-1.0 \mu \mathrm{mol})$.

For ex vitro analyses, two replicate sub-samples were taken from each tissue sample per genotype. These sub-samples were averaged to estimate starch and TSS contents.

Experimental designs and statistical analyses. All experiments were arranged in completely randomized designs. For photosynthesis measurements, each plant per genotype was considered a replication. For carbohydrate and enzymatic analyses, all shoots or roots obtained from each vessel were considered a replication. Main treatment effects and interactions were evaluated using general linear model procedures developed by Statistical Analysis System (SAS Institute Inc., 1999) and mean separation was evaluated using Waller-Duncan's test at $P \leq 0.05$.

\section{Results}

Photosynthetic and transpiration status ex vitro. The ability of plantlets to acclimatize to ex vitro conditions differed significantly between genotypes. EK 16-3 plants exhibited nearly 100\% survival after $6 \mathrm{wk}$, whereas EK 11-1 plants started senescing after 2-wk acclimatization, resulting in $29 \%$ survival after 6 -wk ex vitro culture (Fig. 1A). Significant differences in $P_{\mathrm{n}}$ were also observed during initial plant growth ex vitro, with $P_{\mathrm{n}}$ values being greater for EK 163 than EK 11-1 plants (Fig. $1 B$ ). At week 0 , ex vitro $P_{\mathrm{n}}$ for EK 11-1 was $1.9 \mu \mathrm{mol} \mathrm{m} \mathrm{m}^{-2}$, which was significantly lower than $P_{\mathrm{n}}$ of EK 16-3 plants. Surviving EK 11-1 plants exhibited a significant increase of $P_{\mathrm{n}}$ over time that was not significantly different to the $P_{\mathrm{n}}$ of EK 16-3 plants after 5 wk ex vitro culture. Transpiration rates of plants at initial ex vitro transfer were significantly higher for EK 111 than EK 16-3 plantlets. After 1-wk ex vitro culture, transpiration rates in both genotypes increased until after week 3 , when they decreased (Fig. 1C). 


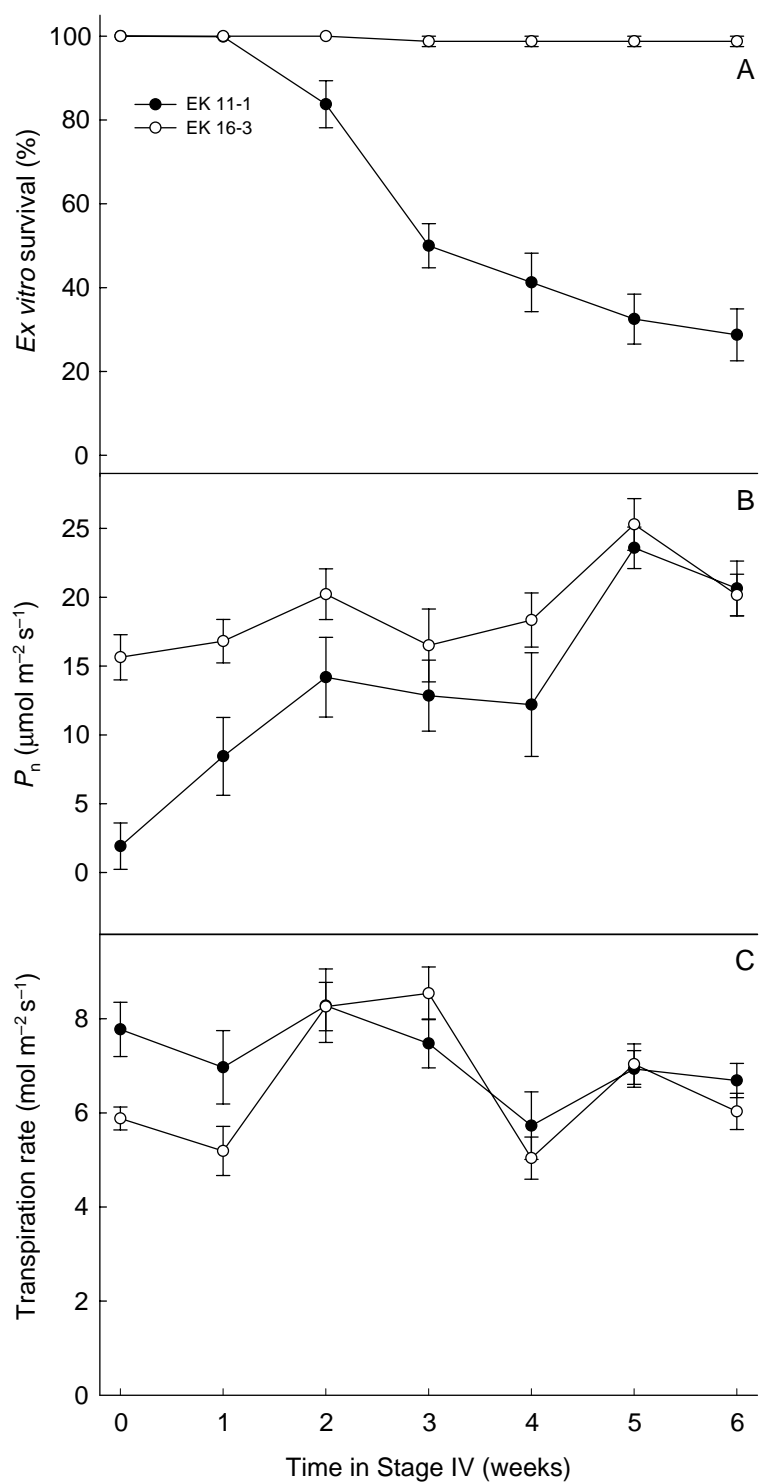

FIG. 1. Effect of in vitro culture conditions on $A$, ex vitro survival; $B$, ex vitro net photosynthetic rate per leaf area $\left(P_{\mathrm{n}}\right)$; and $C$, ex vitro transpiration rate per leaf area, of EK 11-1 and EK 16-3 genotypes during Stage IV culture. Means \pm SE are shown $(n=10)$.

Carbohydrate status in vitro and ex vitro. During weeks 3-9 of Stage III culture, starch content in shoots was greater in EK 11-1 than EK 16-3 plantlets and both genotypes exhibited a steady decrease of shoot starch with time (Fig. 2A). After 6 wk in Stage III, both genotypes exhibited a remarkable decrease in starch content when transferred ex vitro to the greenhouse. By week 4 in Stage IV, shoot starch content of EK 11-1 plantlets was 3.8 times lower than that of EK 16-3 plantlets. Transmission electron micrographs (Fig. 3) of bundle sheath cell chloroplasts indicated differences in the size and the distribution of starch grain chloroplasts with time and between genotypes. While large starch granules were found after $3 \mathrm{wk}$ in Stage III, small starch grains were observed after 6 and 9 wk in Stage III. Chloroplasts in EK 11-1 plantlets after 3 wk in Stage III (Fig. $3 A$ ) exhibited larger numbers of plastoglobuli than in EK 16-3 (Fig. 3D). Furthermore at the same time, thylakoid membranes of EK 11-1 chloroplasts were separated and appeared disrupted (Fig. 3A).

At 6 wk in Stage III, root starch content (Fig. $2 B$ ) was lower in both genotypes compared with shoot starch content (Fig. 2A), and it was not significantly different between genotypes at 6 and $9 \mathrm{wk}$ in Stage III culture. Root starch content also decreased from 6 to $9 \mathrm{wk}$ under Stage III culture conditions. Throughout Stage IV acclimatization, root starch content was similar among genotypes. At 2 wk in Stage IV, root starch content was nearly depleted (13.2 and 6.5 times lower than that of EK 11-1 and EK 16-3, respectively, at week 0).

During Stage III, shoot soluble sugars (sucrose and hexose) increased from weeks 0 to 3 and then gradually decreased from weeks 3 to 9 (Fig. $4 A-C$ ). At 0 wk in Stage III (after 8 wk in Stage II), there was significantly higher shoot sucrose content per dry weight in EK 16-3 than EK 11-1 plantlets, whereas hexose and TSS were non-significantly different between genotypes. Although shoot sucrose, hexose, and TSS were similar among genotypes at 3 and $9 \mathrm{wk}$ in Stage III, at $6 \mathrm{wk}$, sucrose content was $21 \%$ greater in EK 11-1 shoots than EK 16-3 shoots. During Stage IV (after 6 wk in Stage III), shoot soluble sugars decreased from weeks 0 to 2 , and then remained steady from weeks 2 to 4 (Fig. $4 A-C$ ). Furthermore, EK 16-3 plants exhibited significantly higher hexose and TSS contents than EK 11-1 plants after 2 and 4 wk ex vitro.

During Stage III, root soluble sugars (sucrose and hexose) decreased similarly among genotypes between weeks 6 and 9 (Fig. 5 $A-C)$. Sucrose, hexose, and TSS contents in roots were significantly higher for EK 11-1 than EK 16-3 plantlets, and decreased after 9 wk in Stage III in both genotypes (Fig. $5 A-C$ ). During Stage IV (after $6 \mathrm{wk}$ in Stage III), root sucrose and hexose of both genotypes dramatically decreased within $2 \mathrm{wk}$, being nearly depleted during acclimatization.

Chlorophyll and soluble protein contents. Total chlorophyll content was relatively low $\left(0.2 \mathrm{mg} \mathrm{g}^{-1} \mathrm{FW}\right)$ throughout Stage III (EK 11-1) and for the first $3 \mathrm{wk}$ of Stage III culture (EK 16-3). Chlorophyll content of EK 16-3 then increased significantly after 6 and 9 wk in Stage III (Fig. 6A). During Stage IV (after 6 wk in Stage III), chlorophyll levels of EK 16-3 plantlets generally increased with time. In EK 11-1 plantlets, the increase in chlorophyll was delayed until after plantlets were established to greenhouse conditions (after $4 \mathrm{wk}$ in Stage IV). Chlorophyll content was significantly greater for EK 16-3 than EK 11-1 plantlets after 2 and $4 \mathrm{wk}$ in Stage IV. Conversely, EK 11-1-acclimatized plants (>6 wk in the greenhouse) exhibited higher chlorophyll levels than EK 16-3 plants.

Total soluble protein (TSP) content in shoots of sea oats genotypes was lowest at the beginning of Stage III for both genotypes and increased with time, being significantly higher for EK 16-3 than EK 11-1 plantlets after 6 and $9 \mathrm{wk}$ in vitro (Fig. 6B). A rapid increase in TSP was observed in EK 16-3 plantlets during the first $4 \mathrm{wk}$ after transfer to ex vitro conditions, with a significant decrease after plantlets were established ex vitro ( $>6 \mathrm{wk}$ ). EK 11-1 plantlets also increased their TSP content with time, being higher after plants had acclimatized ex vitro.

Photosynthetic enzyme status in vitro and ex vitro. During Stages III and IV, there were significant differences in PEPC activity per gram fresh weight over time and between genotypes (Fig. 7A). EK 16-3 plantlets exhibited higher activity of PEPC with time under Stage III conditions that was also significantly higher 


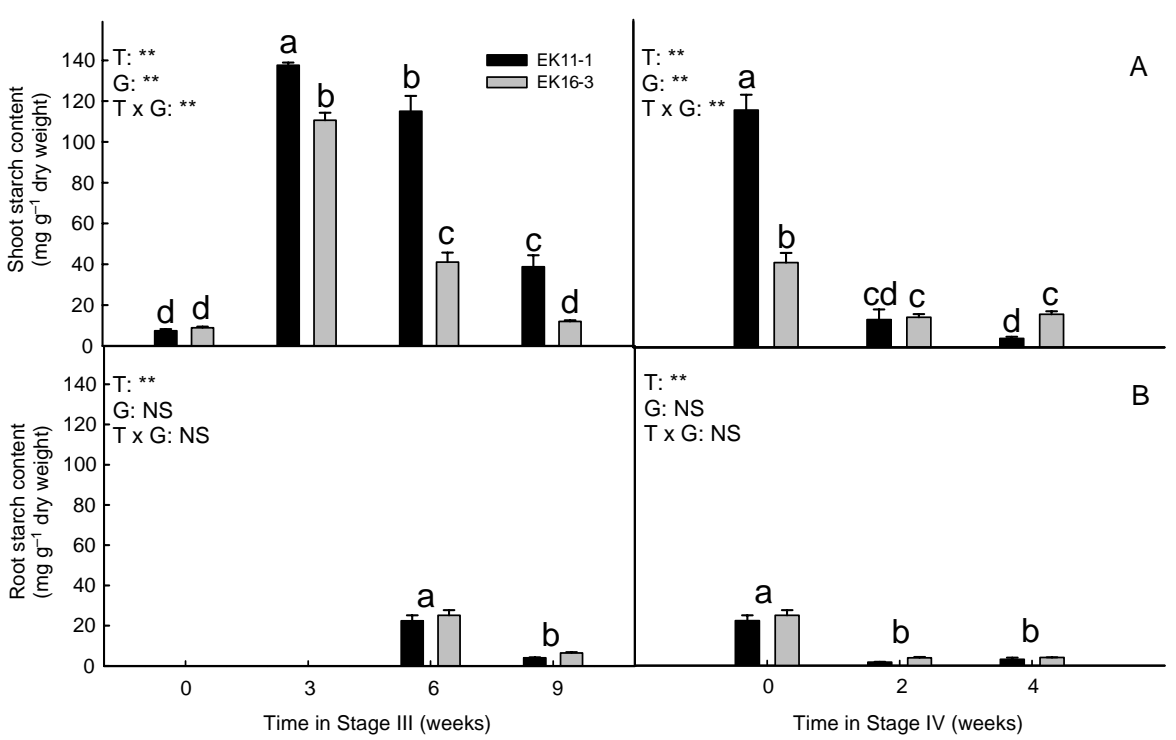

FIG. 2. A, Shoot starch content and B, root starch content of EK 11-1 and EK 16-3 genotypes during in vitro Stage III (left) and after microcuttings were rooted for $6 \mathrm{wk}$, Stage III and transferred to Stage IV $(r i g h t)$. Error bars indicate SE $(n=10)$. ANOVA analysis is shown on top left corner of each graph: T, time; G, genotype; NS, non-significant; ** significant at $P \leq 0.01$. Different letters on top of histobars within each culture stage are significantly different according to the Waller-Duncan test at $P \leq 0.05$.

than EK 11-1 plantlets. Both genotypes increased their PEPC activities following ex vitro transfer. Once the plantlets became established ex vitro $(>6 \mathrm{wk})$, both genotypes had similar PEPC activity.

Differences in rubisco activity were also observed over time and between genotypes during Stage III and after ex vitro transfer to Stage IV (Fig. 7B). EK 11-1 plantlets exhibited a lower rubisco activity per gram fresh weight than EK 16-3 plantlets, which increased after 6 and 9 wk under Stage III conditions. After transferring plantlets to ex vitro conditions (following 6 wk Stage III), rubisco activity did not significantly increase in EK 11-1 plantlets until they were established ex vitro ( $>6 \mathrm{wk})$. Conversely, rubisco activity significantly increased in EK 16-3 plantlets after 2 wk ex vitro but it decreased after plants were established ( $>6 \mathrm{wk}$ ).

The PEPC and rubisco activities of maize (Zea mays L.) plants cultured under greenhouse conditions were assayed following the identical analytical procedures used for sea oats, and a PEPC/rubisco (P/R) ratio of 3.7 was obtained. Similarly, P/R ratios ranging from 3 to 5 were observed in sea oats cultures ex vitro (Fig. 7C). Conversely, lower $\mathrm{P} / \mathrm{R}$ values were observed when sea oats were cultured under Stage III conditions. EK 16-3 plantlets had higher P/R ratios than EK 11-1 plantlets after 9 wk in vitro, but

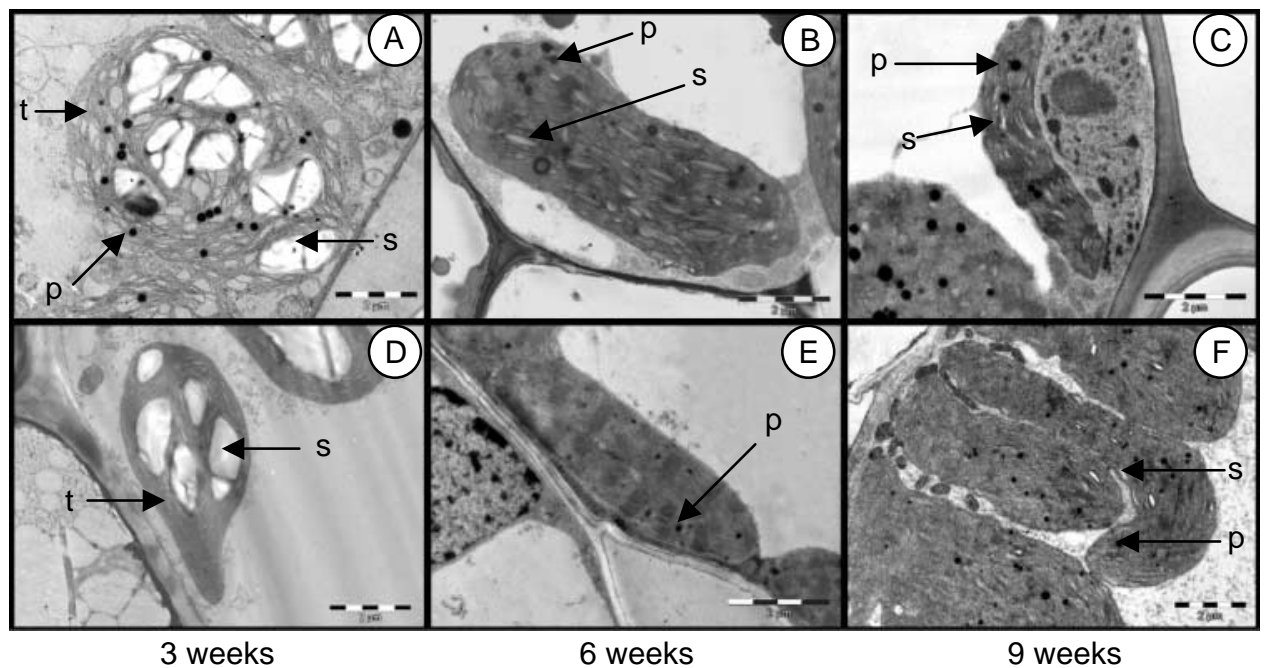

FIG. 3. Comparative TEM of chloroplasts of $A-C$, EK $11-1$ and $D-F$, EK 16-3 genotypes after $(A, D) 3$ wk, $(B, E) 6$ wk, and $(C, F)$ 9 wk Stage III culture conditions in bundle sheath cells. Bar $=2 \mu \mathrm{m}$. p, Plastoglobuli; s, starch granule; and t, thylakoid membranes. 


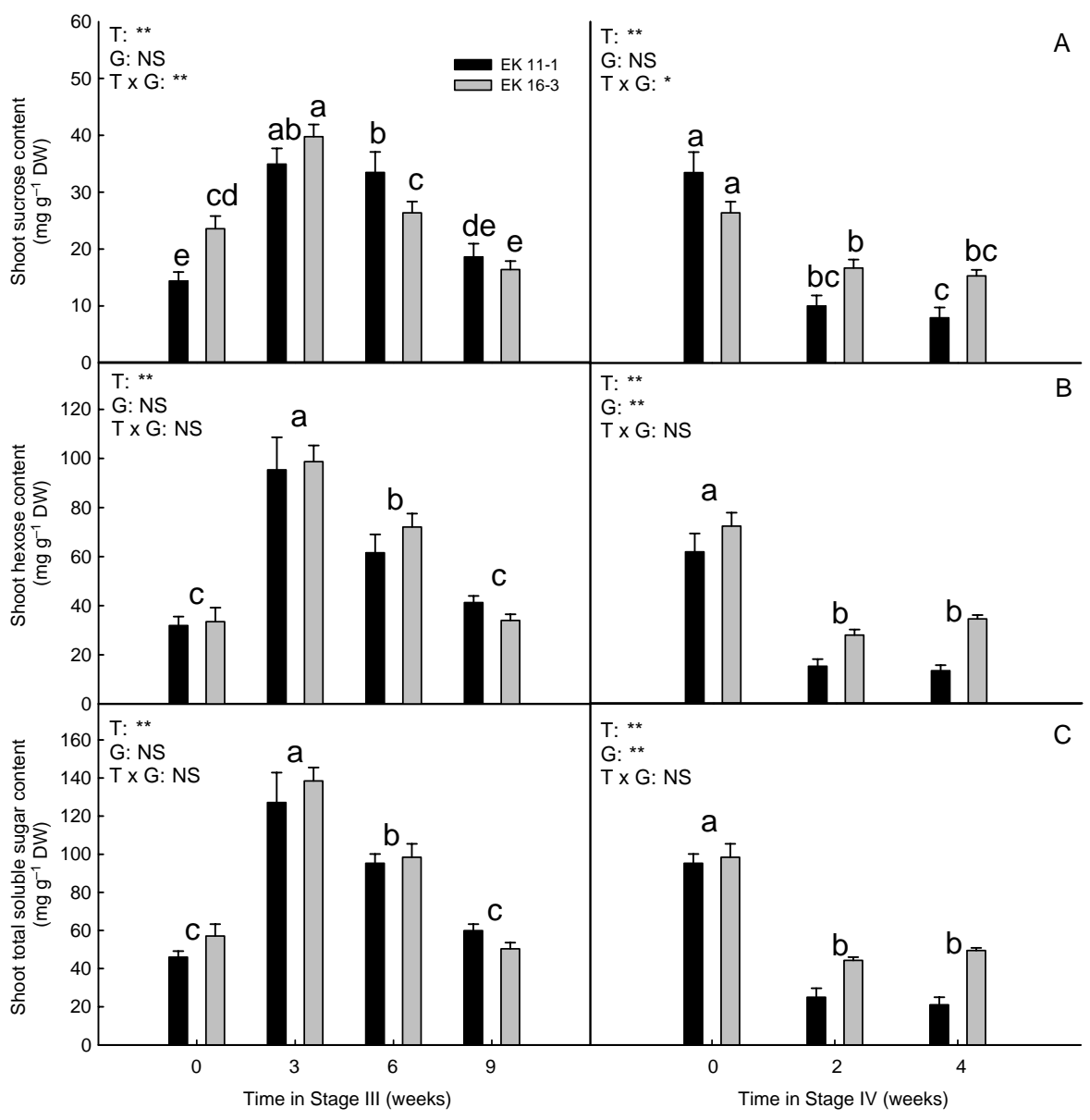

FIG. 4. $A$, Shoot sucrose content; $B$, shoot hexose content; and $C$, shoot total soluble sugar content of EK 11-1 and EK 16-3 genotypes during in vitro Stage III (left) and after microcuttings were rooted for $6 \mathrm{wk}$, Stage III and transferred to Stage IV (right). Error bars indicate $\mathrm{SE}(n=10)$. ANOVA analysis is shown on top left corner of each graph: T, time; G, genotype; NS, non-significant; *** significant at $P \leq 0.05$, or 0.01 , respectively. Different letters on top of histobars within each culture stage are significantly different according to the Waller-Duncan test at $P \leq 0.05$.

there were no significant differences between genotypes after transfer to Stage IV conditions.

Photosynthetic enzyme analyses expressed on basis of TSP indicated that PEPC activity was not affected by Stage III duration in EK 11-1 plantlets, but increased in weeks 6 and 9 of Stage III in EK 16-3 plantlets (Fig. 8A). Plantlets of either genotype exhibited from 1.5 to 3.9 times greater PEPC activities after ex vitro acclimatization than at the time of initial transfer (week 0 ). Conversely, rubisco activity per TSP did not vary from 6 wk in Stage III or after ex vitro transfer in either genotype. Additionally, rubisco activity per TSP was significantly higher in EK 16-3 after 6 and $9 \mathrm{wk}$ in vitro and during ex vitro acclimatization than EK 11-1 plantlets (Fig. 8B).

\section{Discussion}

Differences in acclimatization capacities between sea oats genotypes involved remarkable and divergent developmental and physiological responses to in vitro culture conditions. Low ex vitro survival in the EK 11-1 genotype correlated to in vitro development of short leaves having short blades with minimal blade expansion. In contrast, EK 16-3 cultures produced elongated leaves with expanded blades in Stage III by week 6. These leaves were morphologically similar to those produced ex vitro on acclimatized plants. Physiologically, these leaves, like those in red raspberry (Rubus idaeus L.) (Donnelly and Vidaver, 1984) and Asian white birch [Betula platyphylla 'Szechuanica' (Schneid.) Rehd.] (Smith et al., 1986), did not deteriorate rapidly after transplantation and were photosynthetically competent ex vitro. The $P_{\mathrm{n}}$ in EK 16-3 leaves at time of ex vitro transfer was eight times greater than EK 11-1 leaves. Thus, there was a strong correlation between in vitro production of sea oats leaves morphologically similar to those produced ex vitro and photosynthetic competence.

Given that transpiration rates were significantly different at the time of ex vitro transfer, initial poor control of water loss ex vitro most likely contributed to lower EK 11-1 survival. Initial decreases in transpiration rates during week 1 in both genotypes possibly reflect restricted water uptake due to limited root hair development in vitro. After week 1 , the increase in transpiration rates of both genotypes possibly reflects the impact of the greater functioning root 


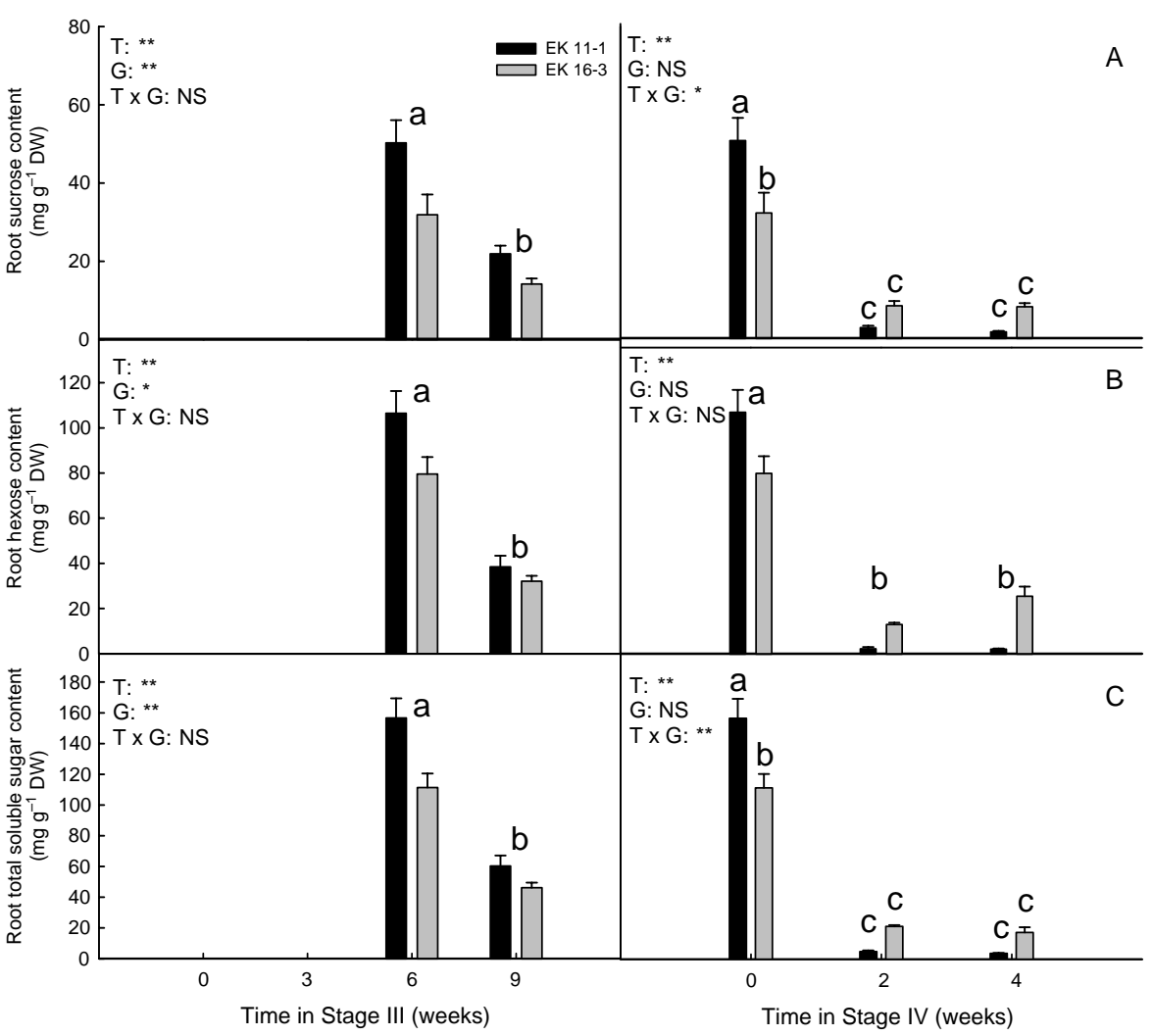

Fig. 5. A, Root sucrose content; $B$, root hexose content; and $C$, root total soluble sugar content of EK 11-1 and EK 16-3 sea oats genotypes during in vitro Stage III (left) and after microcuttings were rooted for 6 wk, Stage III and transferred to Stage IV (right). Error bars indicate SE $(n=10)$. ANOVA analysis is shown on top left corner of each graph: T, time; G, genotype; NS, non-significant; *** significant at $P \leq 0.05$ or 0.01 , respectively. Different letters on top of histobars within each culture stage are significantly different according to the Waller-Duncan test at $P \leq 0.05$.

system combined with the occurrence of abnormal stomate function. Transpiration rates measured after $6 \mathrm{wk}$ ex vitro transfer were similar in both genotypes and likely reflected measurements of surviving plants that had become acclimatized. However, due to the small magnitude, albeit significant, difference in transpiration rates between genotypes at time of ex vitro transfer, we conclude that control of water loss was probably not the main cause for poor ex vitro acclimatization. Although high transpiration rates may exacerbate the transition to ex vitro conditions, other physiological limitations, including poor photosynthetic capacity or limited carbohydrate reserves during acclimatization, had a greater impact on survival of EK 11-1 ex vitro.

Starch accumulation and utilization in plant cells prior to the initiation and progression of developmental processes, such as shoot and root initiation, have been correlated (Swarnkar et al., 1986; Branca et al., 1994). The low initial starch levels in both sea oats genotypes, obtained from 8-wk-old Stage II cultures, indicated that the shoot clusters from which microcuttings were derived, were starch depleted at the end of the multiplication stage. Starch content increased rapidly after microcuttings were transferred to sucrose-containing Stage III medium, prior to root emergence. Rapid accumulation of starch was also observed when begonia (Begonia rex) explants were transferred to medium containing $87.6 \mathrm{~m} M$ sucrose prior the formation of shoot-bud primordia (Mangat et al., 1990). Greater decline in starch reserves in EK 16-3 over EK 11-1 after 3 wk in vitro may have resulted from the more rapid and earlier initiation and growth of EK 16-3 roots and shoots. This observation is supported by comparative growth measurements of both genotypes during Stage III culture (Valero-Aracama, 2005).

Our studies indicated that sea oats genotypes stored starch and contained soluble sugars in shoots and roots throughout Stage III. At the time of acclimatization, starch storage was greater in shoots of EK 11-1 than EK 16-3 plantlets, whereas shoot soluble sugar content was not significantly different between genotypes. During acclimatization ex vitro, shoot starch and soluble sugars in both genotypes were depleted, yet EK 16-3 maintained higher carbohydrate levels than EK 11-1 ex vitro. This was due, in part, to the higher net photosynthetic rates of EK 16-3 leaves at time of ex vitro transfer. During acclimatization, EK 16-3 utilized two carbon sources, namely stored carbohydrate reserves and photoassimilates. In contrast, EK 11-1 plants depended primarily on stored carbohydrate reserves. Given that starch levels were actually higher in shoots of the difficult-to-acclimatize sea oats genotype (EK 11-1) at the time of ex vitro transfer, low ex vitro survival probably resulted from limited production of photosynthetically competent leaves in vitro and subsequent rapid depletion of energy reserves ex vitro. This is supported by the very low $P_{\mathrm{n}}$ in EK 11-1 plantlets during the time of transfer to ex vitro conditions.

Capellades et al. (1991) described an inverse relationship between starch content in shoot chloroplasts and photosynthetic 


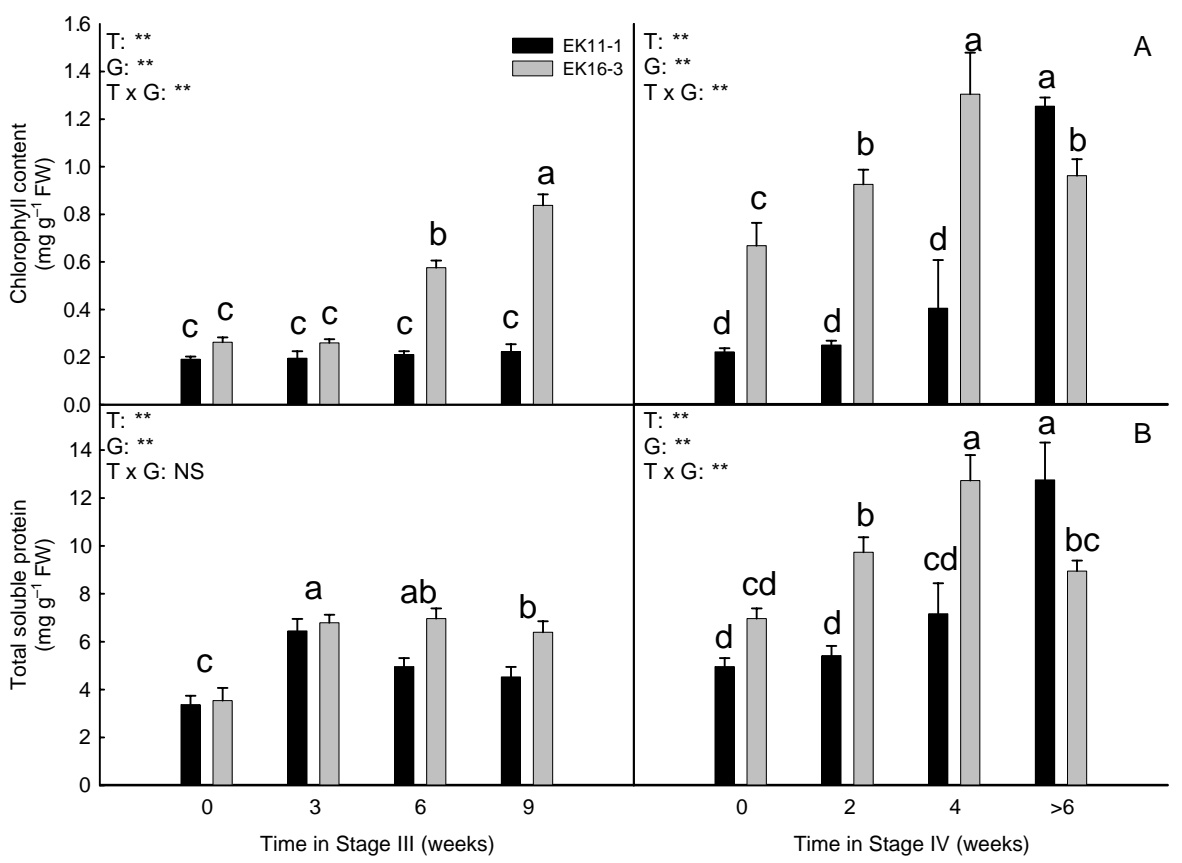

FIG. 6. A, Chlorophyll content per shoot gram fresh weight and B, TSP content per shoot gram fresh weight of EK 11-1 and EK 16-3 sea oats genotypes during in vitro Stage III (left) and after microcuttings were rooted for $6 \mathrm{wk}$, Stage III and transferred to Stage IV (right). Error bars indicate SE $(n=4)$. ANOVA analysis is shown on top left corner of each graph: T, time; G, genotype; NS, non-significant; *,** significant at $P \leq 0.01$, respectively. Different letters on top of histobars and next to legend within each culture stage are significantly different according to the Waller-Duncan test at $P \leq 0.05$.

rates of in vitro rose (Rosa multiflora L. 'Montse') leaves. Additionally, low photosynthetic rates in vitro have also been attributed to carbohydrate accumulation in the leaves (AzcónBieto, 1983). A similar effect may occur during early stages of sea oats in vitro development, when starch and soluble sugar contents in leaves are high. At 3 wk in Stage III, EK 11-1 chloroplasts also exhibited large number of plastoglobuli and separation of thylakoid membranes. These features are often observed in senescing leaves (Arntzen and Briantais, 1975). Plastoglobuli apparently function as extralamellar pools for membrane lipids, utilized for membrane biosynthesis or for deposit after membrane degradation.

In vitro leaves usually serve as storage organs to cover metabolic demands of growing tissues during the initial days of acclimatization (Capellades et al., 1991; Van Huylenbroeck and Debergh, 1996; Piqueras et al., 1998; Van Huylenbroeck et al., 1998; Fuentes et al., 2005). Capellades et al. (1991) also concluded that during ex vitro acclimatization of rose, plants with leaves that exhibited low photosynthetic rates utilized starch reserves while reestablishing the photosynthetic capacity of leaves. However, in other species, only leaves produced ex vitro are photosynthetically competent (Grout and Millam, 1985). Leaves in EK 11-1 plants exhibited low photosynthetic capacity and utilized stored starch reserves during acclimatization. The subsequent high ex vitro mortality indicated that, in most EK 11-1 plants, the respiratory demands were too high to allow restoration of photosynthetic capacity in in vitro-produced leaves or through production of new leaves. In these plants, the allocation of energy resources appears to be directed mostly towards maintenance of root biomass and nonleafy shoot production.
During Stage III culture, starch content in roots of both genotypes was lower than shoots and was similarly depleted ex vitro. Soluble sugar levels were higher in EK 11-1 than EK 16-3 roots during Stage III, but those levels decreased significantly after ex vitro transfer in both genotypes. Sucrose in the medium is hydrolyzed by the enzyme invertase that is released by microcuttings in response to wounding (De la Viña et al., 1999; Sturm, 1999). Then roots uptake sucrose and hexose, which are translocated and stored as starch in shoots and roots in vitro. In contrast, under ex vitro conditions, photosynthetically active leaves are the sources of carbon, where soluble sugars are produced and either stored as starch reserves or translocated into other sink organs, such as roots. Photoassimilates produced during acclimatization in either genotype were translocated and utilized for growth and development, rather than accumulated as starch. This was indicated by the maintenance of low starch levels after 2 and 4 wk ex vitro.

The low photosynthetic capacity of EK 11-1 in vitro-produced leaves can be attributed to the alteration in the activities of the two primary enzymes of $\mathrm{CO}_{2}$ fixation, namely PEPC and rubisco, during in vitro culture and initial ex vitro acclimatization. Rubisco activity in vitro has been reportedly reduced by medium supplementation with exogenous sucrose in $\mathrm{C}_{3}$ species, such as strawberry (Hdider, 1994; Desjardins, 1995) and plantain (Musa AAB cv. CEMSA 3/4) (Aragón et al., 2005). This may, in turn, cause feedback inhibition of photosynthesis because of low phosphate or high sugar-phosphate concentration in the cytosol, both known to affect the regeneration of the rubisco substrate RuBP. Additionally, $\mathrm{C}_{3}$ plants exhibit increased respiration, resulting in increased PEPC activity (Hdider and Desjardins, 1994). Increased PEPC activity has also been reported in the $\mathrm{C}_{4}$ species Flaveria bidentis, when fed with 


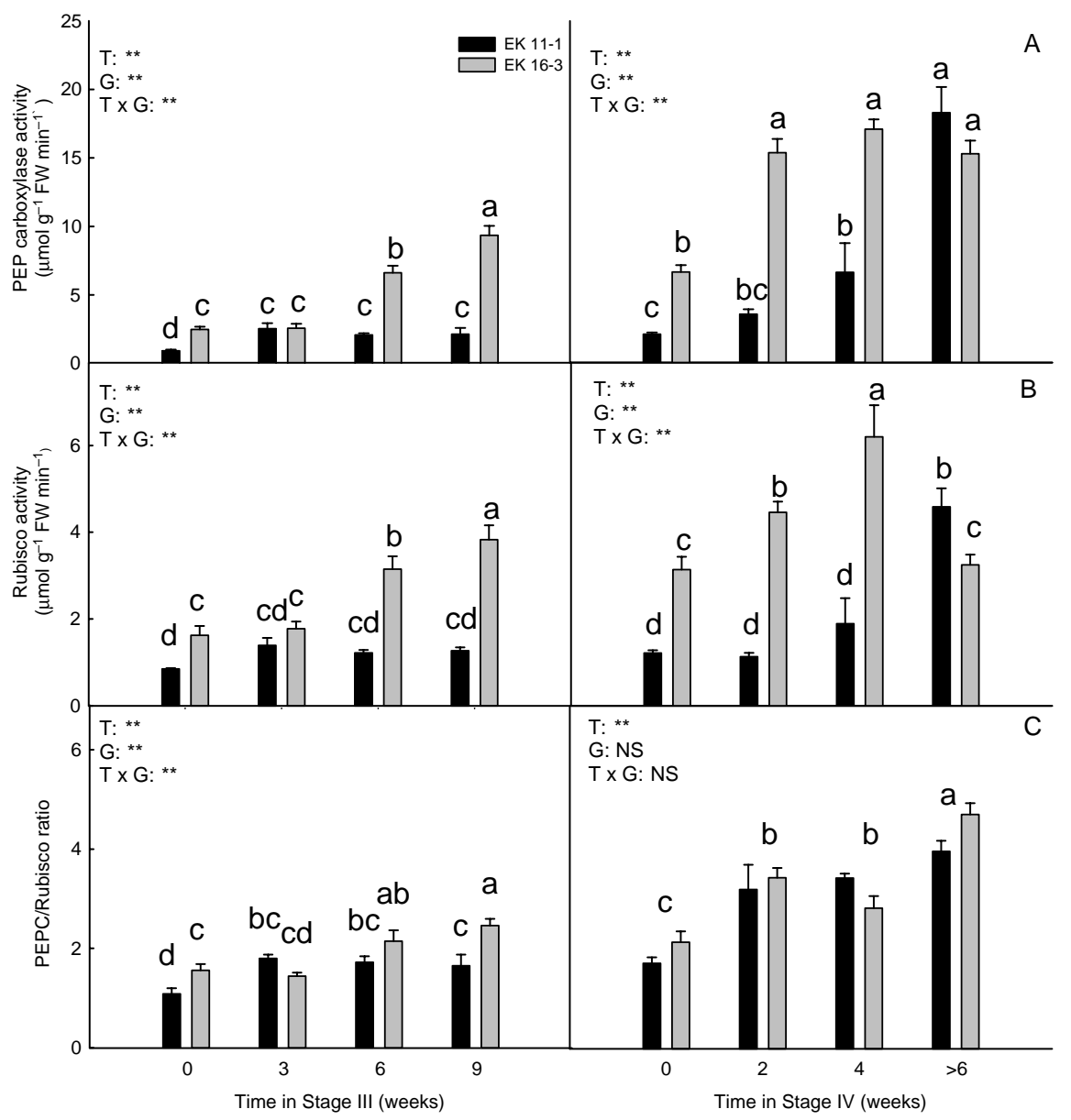

FIG. 7. A, Rubisco activity per shoot gram fresh weight; $B, \mathrm{PEPC}$ activity per shoot gram fresh weight; and $C, \mathrm{PEPC/rubisco} \mathrm{ratio} \mathrm{of}$ EK 11-1 and EK 16-3 sea oats genotypes during in vitro Stage III (left) and after microcuttings were rooted for 6 wk, Stage III and transferred to Stage IV $(r i g h t)$. Error bars indicate SE $(n=4)$. ANOVA analysis is shown on top left corner of each graph: T, time; G, genotype; NS, non-significant; ** significant at $P \leq 0.01$. Different letters on top of histobars within each culture stage are significantly different according to the Waller-Duncan test at $P \leq 0.05$.

146.1 $\mathrm{m} M$ exogenous sucrose in the culture medium (Furbank et al., 1997). In contrast, rubisco activity per TSP did not significantly change in either sea oats genotype after ex vitro transfer. Furthermore, decreased PEPC activity per TSP caused by in vitro conditions was observed in both genotypes. Similar results have been observed in plantain (Aragón et al., 2005). Ex vitro P/R ratios for sea oats averaged 3.6, which was comparable to the $\mathrm{P} / \mathrm{R}$ ratio we obtained with maize. However, in vitro $\mathrm{P} / \mathrm{R}$ ratios were lowered, possibly by the reduced PEPC activity measured.

During weeks 6 and 9 of Stage III culture, the activities of PEPC and rubisco and the contents of chlorophyll and TSP were significantly greater in EK 16-3 than EK 11-1. Histological sections of in vitro-produced leaves of EK 11-1 and EK 16-3 (Valero-Aracama, 2005) indicated that after 6 wk in Stage III, EK 16-3 leaves exhibited more typical Krantz anatomy of $\mathrm{C}_{4}$ plants than EK 11-1 leaves. After 6 wk in Stage III, the fixation of $\mathrm{CO}_{2}$ by PEPC and the $\mathrm{CO}_{2}$ concentrating mechanism in EK 16-3 might have reduced some of the inefficacy of rubisco under the stress caused by in vitro conditions, enabling the maintenance of photosynthesis (Rodríguez et al., 2003). Likewise in sugarcane (Saccharum officinarum L.) plants, a typical $\mathrm{C}_{4}$ species
(Crafts-Brandner and Salvucci, 2002), photosynthesis was tolerant of relatively high environmental stress. Additionally, in vitro sugarcane leaves exhibited minimal Krantz anatomy compared with the more typical Krantz anatomy exhibited by ex vitro leaves (Rodríguez et al., 2003).

This increase in enzymatic activity, chlorophyll and soluble protein content after $6 \mathrm{wk}$ in Stage III correlates with the initial decrease of starch and soluble carbohydrates in shoots of both genotypes during the same time period, and with the formation of the first fully expanded leaves with typical Krantz anatomy in EK 16-3 (Valero-Aracama, 2005). These increased levels of chlorophyll and TSP content and increased enzymatic activities are indicative of the development of photosynthetic characteristics in EK 16-3 after 6 wk in Stage III. Furthermore, EK 16-3 plantlets transferred ex vitro after $6 \mathrm{wk}$ in Stage III exhibited 100\% survival. Conversely, EK 11-1 plants exhibited limited leaf elongation and expansion during Stage III culture (Valero-Aracama, 2005), which correlated with lower PEPC and rubisco activities, and low chlorophyll and TSP contents in vitro compared to EK 16-3 plants. This limited development of photosynthetic features in vitro resulted in $30 \%$ survival after $6 \mathrm{wk}$ ex vitro conditions. 


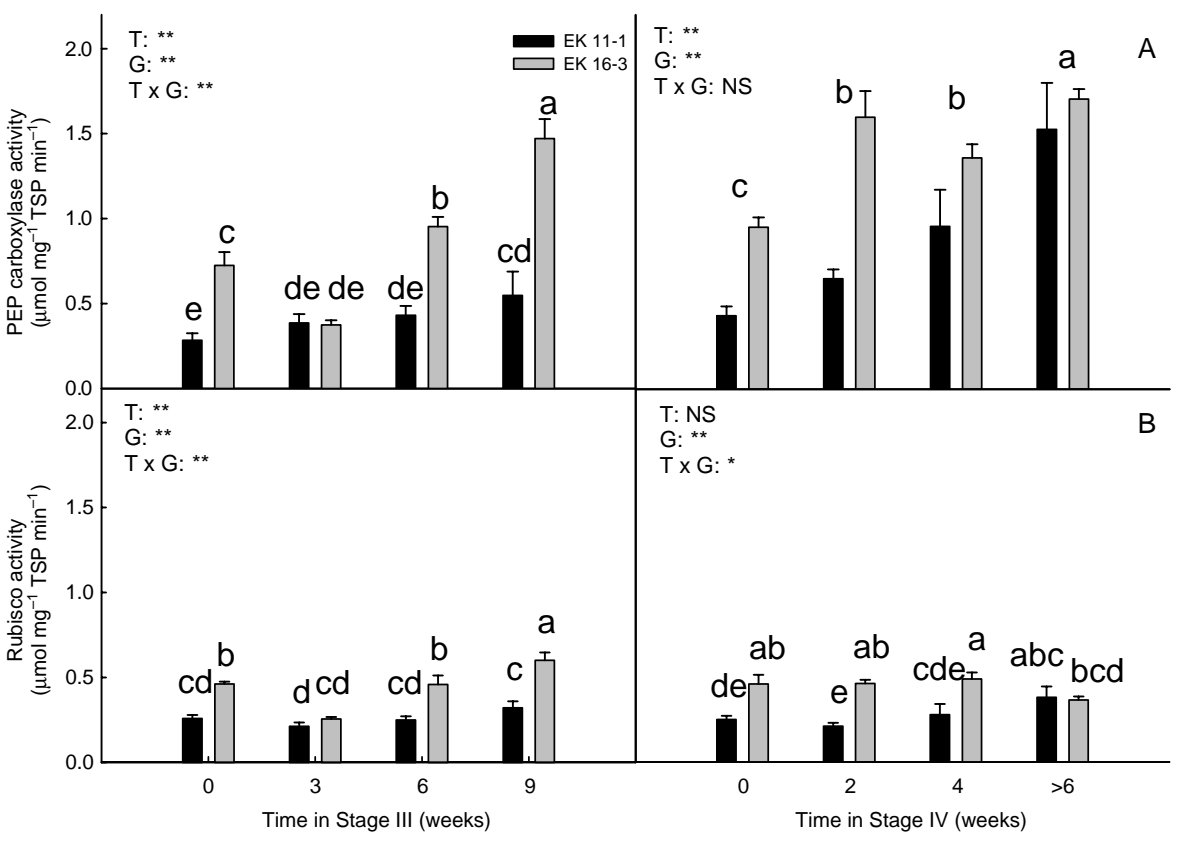

FIG. 8. A, PEPC activity per shoot milligram total soluble protein (TSP) and $B$, rubisco activity per shoot milligram TSP of EK 11-1 and EK 16-3 sea oats genotypes during in vitro Stage III (left) and after microcuttings were rooted for 6 wk, Stage III and transferred to Stage IV (right). Error bars indicate SE $(n=4)$. ANOVA analysis is shown on top left corner of each graph: T, time; G, genotype; NS, nonsignificant; *** significant at $P \leq 0.05$ or $P \leq 0.01$, respectively. Different letters on top of histobars and next to legend within each culture stage are significantly different according to the Waller-Duncan test at $P \leq 0.05$.

\section{Conclusions}

Lower photosynthetic capacity $\left(P_{\mathrm{n}}\right)$ of EK 11-1 than EK 16-3 at time of transfer to ex vitro conditions was correlated with reduced survival. In addition to lower photosynthetic capacity ex vitro, other factors, including initially higher transpiration rates and insufficient carbohydrate reserves to facilitate the transition from in vitro to ex vitro conditions, further contributed to poor ex vitro survival in EK 11-1.

Carbohydrate analyses indicated rapid accumulation of starch and sugars in plantlets for the first $3 \mathrm{wk}$ following transfer to Stage III medium in both genotypes. These carbohydrates were used for root and shoot initiation and growth during the later Stage III culture period. Carbohydrate reserve utilization in EK 16-3 during the late Stage III culture period was greater than EK 11-1, and resulted in lower starch and soluble sugar reserves than EK 11-1 at the time of ex vitro transfer. After $6 \mathrm{wk}$ in Stage III, there were significantly greater increases in PEPC and rubisco activities, and in chlorophyll and TSP contents in EK 16-3 than EK 11-1 plantlets. These differences correlated with the development of anatomical and morphological leaf features similar to those in the greenhouseproduced leaves (Valero-Aracama, 2005).

Stage III in vitro culture conditions differently affected the growth and development of photosynthetic capacity of sea oats genotypes. Those genotypes capable of developing photosynthetically competent leaves, while storing carbohydrates in vitro, can overcome the energy demands to feed respiration requirements of cells, as well as to feed growth requirements of different organs during acclimatization. Difficult-to-acclimatize sea oats genotypes could possibly benefit from modifications of the in vitro culture conditions, such as alteration of the environmental culture conditions or the medium components, for improved ex vitro acclimatization.

\section{ACKNowledgments}

This project was developed under the guidance of the Florida Sea Grant College Program and funded from NOAA, Department of Commerce, Grant No. NA16RG-2195. The authors would like to thank Carolyn Bartuska for her statistical expertise, Chris Wilson for his HPLC instrumentation, and Karen Kelley and Fred Bennett in the Electron Microscopy Core Laboratory at the UF, for their guidance and assistance in histological studies.

\section{References}

Aragón, C. E.; Escalona, M.; Capote, I.; Pina, D.; Cejas, I.; Rodriguez, R.; Cañal, M. J.; Sandoval, J.; Roels, S.; Debergh, P.; Gonzalez-Olmedo, J. Photosynthesis and carbon metabolism in plantain (Musa AAB) plantlets growing in temporary immersion bioreactors and during $e x$ vitro acclimatization. In Vitro Cell. Dev. Biol.-Plant 41:550-554; 2005.

Arigita, L.; González, A.; Sánchez Tamés, R. Influence of $\mathrm{CO}_{2}$ and sucrose on photosynthesis and transpiration of Actidinia deliciosa explants cultured in vitro. Physiol. Plant. 115:166-173; 2002.

Arnon, D. I. Copper enzymes in isolated chloroplasts; polyphenol oxidases in Beta vulgaris. Plant Physiol. 24:1-15; 1949.

Arntzen, C. J.; Briantais, J. M. Chloroplast structure and function. In: Govindjee, ed. Bioenergetics of photosynthesis. New York: Academic Press; 1975:51-113.

Ashton, A. R.; Burnell, J. N.; Furbank, R. T.; Jenkins, C. L. D.; Hatch, M. D. Enzymes of $\mathrm{C}_{4}$ photosynthesis. Meth. Plant Biochem. 3:39-72; 1990.

Azcón-Bieto, J. Inhibition of photosynthesis by carbohydrates in wheat leaves. Plant Physiol. 73:681-686; 1983.

Bachman, G. R.; Whitwell, T. Nursery production of Uniola paniculata (southern sea oats). HortTechnology 5:296-298; 1995. 
Boersig, M. R.; Negm, F. B. Prevention of sucrose inversion during preparation of HPLC samples. HortScience 20:1054-1056; 1985.

Bradford, M. M. A rapid and sensitive method for the quantification of microgram quantities of protein utilizing the principle of protein dyebinding. Anal. Biochem. 72:248-254; 1976.

Branca, C.; Torelli, A.; Fermi, P.; Altamura, M. M.; Bassi, M. Early phases of in vitro culture tomato cotyledons: starch accumulation and protein pattern in relation to the hormonal treatment. Protoplasma 182:59-64; 1994.

Brown, W.; Smith, B. N. The Kranz syndrome in Uniola (Gramineae). B. Torrey Bot. Club 101:117-120; 1974.

Burgess, T. L.; Blazich, F. A.; Nash, D. L. Seed germination of southern seaoats (Uniola paniculata) as influenced by stratification, temperature, and light. J. Environ. Hort. 20:180-183; 2002.

Burgess, T. L.; Blazich, F. A.; Nash, D. L.; Randall-Schadel, B. Influence of selected surface disinfestants, fungicides, and temperature on seed germination and initial growth of southern seaoats (Uniola paniculata). J. Environ. Hort. 23:4-8; 2005.

Capellades, M.; Lemeur, R.; Debergh, P. Effects of sucrose on starch accumulation and rate of photosynthesis in Rosa cultured in vitro. Plant Cell Tissue Organ Cult. 25:21-26; 1991.

Crafts-Brandner, S. J.; Salvucci, M. E. Sensitivity of photosynthesis in a C4 plant, maize, to heat stress. Plant Physiol. 129:1773-1780; 2002

De, Y.; Gosselin, A.; Desjardins, Y. Re-examination of photosynthetic capacity of in vitro-cultured strawberry plantlets. J. Am. Soc. Hort. Sci. 118:419-424; 1993.

Debergh, P. C.; Zimmerman, R. H. Micropropagation: technology and application. Dordrecht, The Netherlands: Kluwer Academic Publishers; 1991.

De la Viña, G.; Pliego-Alfaro, F.; Driscoll, S.; Mitchell, V.; Parry, M.; Lawlor, D. Effects of $\mathrm{CO}_{2}$ and sugars on photosynthesis and composition of avocado leaves grown in vitro. Plant Physiol. Biochem. 37:587-595; 1999.

Desjardins, Y. Photosynthesis in vitro - on the factors regulating $\mathrm{CO}_{2}$ assimilation in micropropagation systems. Acta Hort. 393:45-57; 1995.

Donnelly, D. J.; Vidaver, W. E. Pigment content and gas exchange of red raspberry in vitro and ex vitro. J. Am. Soc. Hort. Sci. 109:177-181; 1984.

Estrada-Luna, A. A.; Davies, F. T. Jr.; Egilla, J. N. Physiological changes and growth of micropropagated chile ancho pepper plantlets during acclimatization and post-acclimatization. Plant Cell Tissue Organ Cult. 66:17-24; 2001 .

Fuentes, G.; Talavera, C.; Oropeza, C.; Desjardins, Y.; Santamaria, J. M. Exogenous sucrose can decrease in vitro photosynthesis but improve field survival and growth of coconut (Cocos nucifera L.) in vitro plantlets. In Vitro Cell. Dev. Biol.-Plant 41:69-76; 2005.

Furbank, R.; Pritchard, J.; Jenkins, C. Effects of exogenous sucrose feeding on photosynthesis in the $\mathrm{C}_{3}$ plant tobacco and the $\mathrm{C}_{4}$ plant Flaveria bidentis. Aust. J. Plant Physiol. 24:291-299; 1997.

Grout, B. W. W. Photosynthesis of regenerated plantlets in vitro, and the stress of transplanting. Acta Hort. 230:129-135; 1988.

Grout, B. W. W.; Aston, M. J. Transplanting of cauliflower plants regenerated from meristem culture. II. Carbon dioxide fixation and the development of photosynthetic ability. Hort. Res. 17:65-74; 1978.

Grout, B. W. W.; Millam, S. Photosynthetic development of micropropagated strawberry plantlets following transplanting. Ann. Bot. 55:129-131; 1985.

Haissig, B. E.; Dickson, R. E. Starch measurement in plant tissue using enzymatic hydrolysis. Physiol. Plant. 47:151-157; 1979.

Hartmann, H. T.; Kester, D. E.; Davies, F. T. Jr.; Geneve, R. L. Plant propagation: principles and practices, 7th edn, Upper Saddle River: Prentice Hall; 2002.

Hdider, C. Etude du metabolisme carbone et de certains aspects de son interaction avec la nutrition azotee durant la culture in vitro de plantules de fraisier (Fragaria $\times$ ananassa Duch.). Ph.D. Dissertation, Universite Laval, Quebec, Canada; 1994.

Hdider, C.; Desjardins, Y. Effects of sucrose on $P_{\mathrm{n}}$ and phosphoenolpyruvate caroboxylase activity of in vitro cultured strawberry plantlets. Plant Cell Tissue Organ Cult. 36:27-33; 1994.
Hester, M. W.; Mendelssohn, I. A. Seed production and germination response of four Louisiana populations of Uniola paniculata (Gramineae). Am. J. Bot. 74:1093-1101; 1987.

Jeong, B. R.; Fujiwara, K.; Kozai, T. Environmental control and photoautotrophic micropropagation. Hort. Rev. 17:123-170; 1995.

Kozai, T. Controlled environment in conventional and automated micropropagation. In: Vasil, I. K., ed. Cell culture and somatic cell genetics of plants, Vol. 8. New York: Academic Press; 1991:213-228.

Kozai, T. Acclimatization of micropropagated plants. In: Bajaj, Y. P. S., ed. Biotechnology in agriculture and forestry, Vol. 17, High-tech and micropropagation I; Berlin, Heidelberg: Springer-Verlag; 1991:127-141.

Kozai, T.; Iwanami, Y. Effects of $\mathrm{CO}_{2}$ enrichment and sucrose concentration under high photon fluxes on plant growth of carnation (Dianthus caryophyllus L.) in tissue culture during the preparation stage. J. Japan. Soc. Hort. Sci. 57:279-288; 1988.

Lilley, R. McC.; Walker, D. A. An improved spectrophotometric assay for ribulose bisphosphate carboxylase. Biochem. Biophys. Acta 358:226-229; 1974.

Mangat, B. S.; Pelekis, M.; Cassels, A. C. Changes in the starch content during organogenesis in in vitro cultures of Begonia rex stem explants. Physiol. Plant. 79:267-274; 1990.

McDowell, E. M.; Trump, B. F. Histological fixatives suitable for diagnostic light and electron microscopy. Arch. Path. Lab. Med. 100:405; 1976.

Miller, W. B.; Langhans, R. W. Carbohydrate changes of Easter lilies during growth in normal and reduced irradiance environments. J. Am. Soc. Hort. Sci. 114:310-315; 1989.

Murashige, T.; Skoog, F. A revised medium for rapid growth and bioassays with tobacco tissue cultures. Physiol. Plant. 15:473-497; 1962.

Philman, N. L.; Kane, M. E. Micropropagation of Uniola paniculata L. (sea oats) from tiller explants. HortScience 29:559; 1994.

Piqueras, A.; Van Huylenbroeck, J. M.; Han, B. H.; Debergh, P. C. Carbohydrate partitioning and metabolism during acclimatization of micropropagated Calathea. Plant Growth Regul. 26:25-31; 1998.

Pospíśilová, J.; Solárová, J.; Čatský, J. Photosynthetic responses to stress during in vitro cultivation. Photosynthetica 26:3-18; 1992.

Pospísilová, J.; Tichá, I.; Kadleček, P.; Haisel, D.; Plzáková, Š. Acclimatization of micropropagated plants to ex vitro conditions. Biol. Plant. 42:481-497; 1999.

Preece, J. E.; Sutter, E. G. Acclimatization of micropropagated plants to the greenhouse and field. In: Debergh, P.; Zimmerman, R., eds. Micropropagation: technology and application. Dordrecht, The Netherlands: Kluwer Academic Publishers; 1991:71-94.

Ranamukhaarachchi, D. G. Molecular analysis of genetic diversity in Florida sea-oats (Uniola paniculata) populations: new approaches to generate and analyze molecular data. Ph.D. Dissertation, University of Florida, Gainesville, FL; 2000.

Reynolds, E. S. The use of lead citrate at high $\mathrm{pH}$ as an electron opaque stain for electron microscopy. J. Cell. Biol. 17:208-213; 1963.

Rodríguez, R.; Cid, M.; Pina, D.; González-Olmedo, J. L.; Desjardins, Y. Growth and photosynthetic activity during acclimatization of sugarcane plantlets cultivated in temporary immersion bioreactors. In Vitro Cell. Dev. Biol._Plant 39:657-662; 2003.

SAS Institute, Inc.: Version 8.02. Cary, NC: SAS Institute, Inc.; 1999.

Sharkey, T. D.; Savitch, L. V.; Butz, N. D. Photometric method for routine determination of kcat and carbamylation of rubisco. Photosyn. Res. 28:41-48; 1991 .

Sinha, A.; Hofmann, M.; Römer, U.; Köckenberger, E. L.; Roitsch, T. Metabolizable and non-metabolizable sugars activate different signal transduction pathways in tomato. Plant Physiol. 128:1480-1489; 2002.

Smith, M. A. L.; Palta, J. P.; McCown, B. H. Comparative anatomy and physiology of microcultured, seedling, and greenhouse-grown Asian white birch. J. Am. Soc. Hort. Sci. 111:437-442; 1986.

Spurr, A. R. A low-viscosity epoxy resin embedding medium for electron microscopy. J. Ultrastr. Res. 26:31; 1969.

Sturm, A. Invertase: primary structures, functions, and roles in plant development and sucrose partitioning. Plant Physiol. 121:1-8; 1999

Swarnkar, P. L.; Bohra, S. P.; Chandra, N. Biochemical studies on initiation of callus in Solanum surattense. J. Plant Physiol. 126:293-296; 1986. 
Triques, K.; Rival, A.; Beulé, T.; Dussert, S.; Hocher, V. Developmental changes in carboxylase activities in in vitro cultured coconut zygotic embryos: comparison with corresponding activities in seedlings. Plant Cell Tiss. Organ Cult. 39:227-231; 1997.

Valero-Aracama, C. Physiological and anatomical basis for differences in growth performance during in vitro and ex vitro culture of sea oats (Uniola paniculata L.) genotypes. Ph.D. Dissertation, University of Florida, Gainesville, FL; 2005.

Van Huylenbroeck, J.; Debergh, P. C. Impact of sugar concentration in vitro on photosynthesis and carbon metabolism during ex vitro acclimatization of Spathiphyllum plantlets. Phys. Plant. 96:298-304; 1996

Van Huylenbroeck, J.; Piqueras, A.; Debergh, P. C. Photosynthesis and carbon metabolism in leaves formed prior to and during ex vitro acclimatization of micropropagated plants. Plant Sci. 134:21-30; 1998.

Wagner, R. H. The ecology of Uniola paniculata L. in the dune-strand habitat of North Carolina. Ecol. Monogr. 34:79-96; 1964.

Wetzstein, H. Y.; Sommer, H. E. Leaf anatomy of tissue-cultured Liquidambar styraciflua (Hamamelidaceae) during acclimatization. Am. J. Bot. 69:1579-1586; 1982. 